\title{
Anomalous Origin of Left Main Coronary Artery from Right Coronary Artery in A Patient Presenting with Inferior Wall Myocardial Infarction: A Case Report
}

Mohammad Rafiur Rahman ${ }^{1}$, Asma Akter ${ }^{2}$, Arif Ahmed Mohiuddin³, Mohammad Arifur Rahman ${ }^{4}$, Sayedur Rahman Khan $^{5}$, Jahangir Kabir 6

\begin{abstract}
:
Anomalous origin of the coronary arteries is a very rare phenomenon and is seen only in less than $1 \%$ of the general population. Single coronary artery (SCA) is a congenital anatomic abnormality identified by a single coronary ostium giving rise to one coronary artery. Our case presented at $\mathbf{4 0}$ years with intermittent chest discomfort, effort intolerance and a history of getting Streptokinase one month back due to AMI (Inferior). Diagnosis was confirmed with elective conventional coronary angiography and coronary CT angiography as
\end{abstract}

an extremely rare variant of the left main coronary artery (LMCA) branching off from the right coronary artery (RCA) and then following a pre-pulmonic course. We did Off Pump CABG surgery with four grafts and discharged the patient uneventfully with guidelinedirected medical therapy with a beta-blocker, statin, and dual antiplatelet agents and the patient is on follow up.

Key words: Single coronary artery, Coronary artery anomaly, Pre-pulmonic, Anomalous left main coronary artery, CABG

(Bangladesh Heart Journal 2021; 36(1): 61-66)

Introduction:

The term 'coronary artery anomaly' (CAA) is used when the observed coronary pattern is seen in less than $1 \%$ of the general population.1 The overall incidence of CAA has been estimated between $0.9 \%$ and $5.6 \% .2-4$ Based on the origin and course of the anomalous artery, CAA can either represent a benign incidental finding or can have severe cardiovascular sequelae. Coronary computed tomography angiography (CTA) is a reliable non-invasive tool for diagnosing CAA. The management varies based on the nature of symptoms. Here, we present a case of inferior wall ST-elevation myocardial infarction due to distal right coronary artery (RCA) occlusion with incidental findings of anomalous left main coronary artery (LMCA) branching off the RCA.

\section{Case}

A 40-year-old hypertensive and diabetic lady presented to our facility for elective CAG with a h/o AMI (Inferior) approximately one and half months back. Other relevant medical history included effort fatiguability and occasional

1. Junior Consultant, Cardiac Surgery, United Hospital Ltd., Dhaka, Bangladesh

2. Junior Consultant, Pediatrics, Bangladesh Secretariat Clinic, Dhaka, Bangladesh

3. Junior Consultant, Cardiac Surgery, United Hospital Ltd., Dhaka, Bangladesh

4. Junior Consultant, Department of Cardiology, Sorkari Kormochary Hospital, Dhaka, Bangladesh

5. Consultant, Cardiac Surgery, United Hospital Ltd., Dhaka, Bangladesh

6. Chief Cardiac Surgeon \& Director, Cardiac Centre, United Hospital Ltd., Dhaka, Bangladesh

Address of Correspondence: Dr. Mohammad Rafiur Rahman, United Hospital Ltd., Dhaka, Bangladesh. Email: raafirahman35@gmail.com, Mobile no- +8801711247464 
left sided chest pain for two months with a positive family history. On presentation, the patient was haemodynamically stable and physical examination including cardiovascular auscultation was unremarkable. Electrocardiograms (EKG) displayed Q-wave and inverted T-wave in the leads II, III, and AVF (Figure 1A). The patient was admitted under Cardiology department and transferred to the cardiac catheterization lab where she underwent coronary angiogram. After an initial failed attempt to first cannulate the left coronary ostium to evaluate for concomitant left anterior descending (LAD) and circumflex disease with the suspected culprit being the RCA based on EKG, the right coronary ostium was engaged instead, which revealed a large caliber RCA descending through the coronary sulcus to the crux, giving rise to left anterior descending and obtuse marginal branches before giving rise to an early posterior descending artery (Early PDA) and continued to a posterolateral vessel (PLV). Contrast injection into the RCA also showed the anomalous origin of the LMCA stemming from the proximal segment of the RCA. RCA was dominant, good size vessel having 98-99 stenosis at its proximal segment and $70-80$ stenosis at its distal segment. The aberrant LMCA reached the left side of the heart anterior to the pulmonary artery and trifurcated into a small caliber $L A D$, ramus intermedius (RI), and left circumflex (LCX) artery that ends into a bifurcated obtuse marginal system (Figure 2). Patient was then referred back to Cardiac Surgery department for CABG operation. After proper pre operative evaluation among which Transthoracic echocardiogram (TTE) showed an ejection fraction (EF) between $45 \%$ and $50 \%$, basal segment of inferior and inferolateral wall akinesis and no valvular abnormalities (Figure 1B). A coronary CTA confirmed the findings of coronary angiogram and a potential malignant course of anomalous LMCA was ruled out (Figure 3). OffPump Coronary Artery Bypass Surgery with four grafts (OPCAB $\times 04$ grafts) done with Left Internal Mammary Artery (LIMA) to LAD and Reverse Saphenous Vein Graft (RSVG) to OM, Early PDA \& Poster-lateral Vessel (PLV) (Figure 4). Her immediate post-op and further hospital stay remained uneventful, and the patient was discharged home on guideline-directed medical therapy with a betablocker, statin, and dual antiplatelet agents. At 1-month follow-up visit, the patient remained asymptomatic and a repeat TTE showed no new findings.

\section{Course of management:}

\begin{tabular}{|c|c|c|}
\hline Day & Timing & Events \\
\hline Day 1 & 17.08 .2020 & $\begin{array}{l}\text { Patient presents with chest pain in a peripheral hospital. } \\
\text { Diagnosed as having AMI (Inferior). } \\
\text { Treated with Inj. Streptokinase and LMWH. } \\
\text { Started on dual antiplatelet, statin therapy and released with advice for } \\
\text { early CAG. }\end{array}$ \\
\hline Day 43 & 30.09 .2020 & $\begin{array}{l}\text { Elective CAG done at our center. } \\
\text { Which revealed } 98-99 \% \text { stenosis at the proximal segment of LAD, } 70- \\
80 \% \text { stenosis at the proximal segment of } L C X, 98-99 \% \text { stenosis at the } \\
\text { proximal segment of } R C A \text { and } 70-80 \% \text { stenosis at its distal segment } \\
\text { right coronary artery (RCA) lesion and anomalous origin of left main } \\
\text { coronary artery (LMCA) from RCA. } \\
\text { Transthoracic echocardiography is performed which shows mild to } \\
\text { moderately reduced ejection fraction. }\end{array}$ \\
\hline Day 44 & 01.10 .2020 & $\begin{array}{l}\text { Patient is scheduled for coronary computed tomography }(C T) \text { angiography } \\
\text { and Evaluation for CABG. } \\
\text { Coronary CT angiography (on 21.10.2020) demonstrates benign } \\
\text { prepulmonic course of aberrant LMCA. }\end{array}$ \\
\hline Day 74 & 01.11 .2020 & Off Pump CABG Surgery with 04 Grafts done. \\
\hline Day 83 & 10.11.2020 & $\begin{array}{l}\text { Patient discharged on aspirin, clopidogrel, atorvastatin, metoprolol and } \\
\text { furosemide with advice for follow up. }\end{array}$ \\
\hline
\end{tabular}




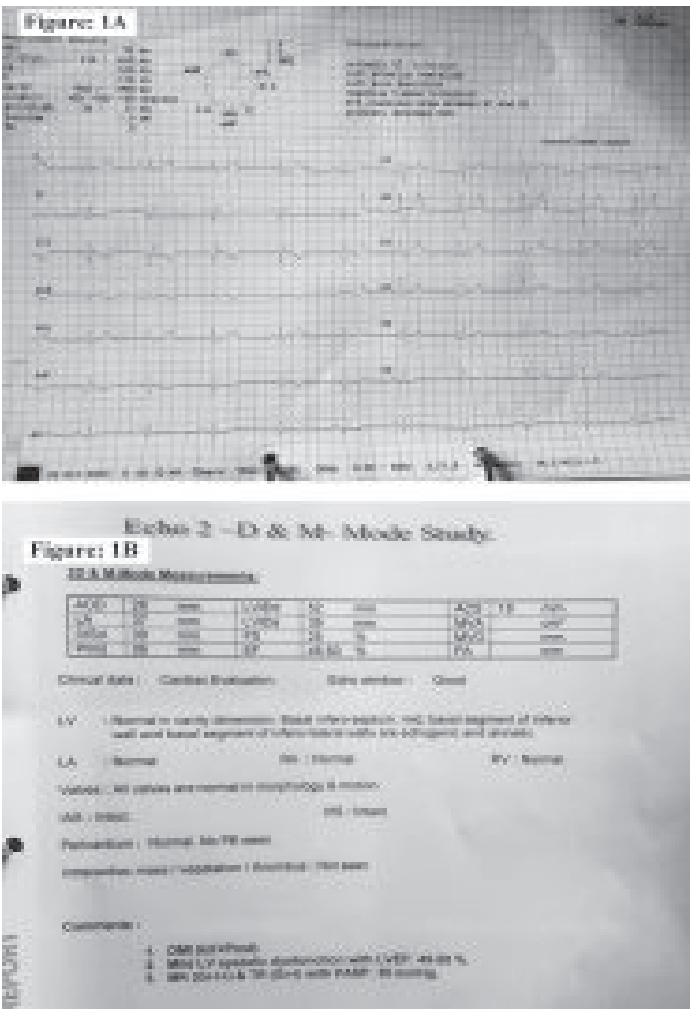

Fig.-1: (A) Electrocardiograms (EKG) displayed Q-wave and inverted T-wave in the leads II, III, and AVF (B) Transthoracic echocardiogram (TTE) showed an ejection fraction (EF) between $45 \%$ and $50 \%$, basal segment of inferior and inferolateral wall akinesis and no valvular abnormalities.

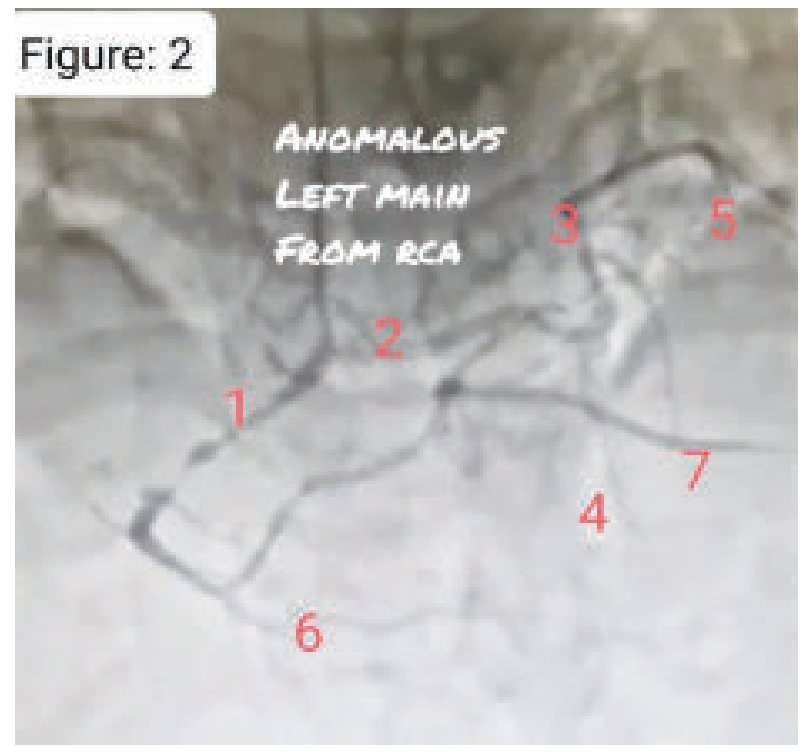

Fig.-2: Contrast injection into the RCA showed the anomalous origin of the LMCA stemming from the proximal segment of the RCA. RCA was dominant, good size vessel having 98-99 stenosis at its proximal segment and 70-80 stenosis at its distal segment. The aberrant $\angle M C A$ reached the left side of the heart anterior to the pulmonary artery and trifurcated into a small caliber $L A D$, ramus intermedius (RI), and left circumflex $(L C X)$ artery that ends into a bifurcated obtuse marginal system. 1 , right coronary artery; 2, left main coronary artery; 3, left circumflex artery; 4, left anterior descending artery; 5, obtuse marginals; 6, early posterior descending artery; 7, postero lateral vessel

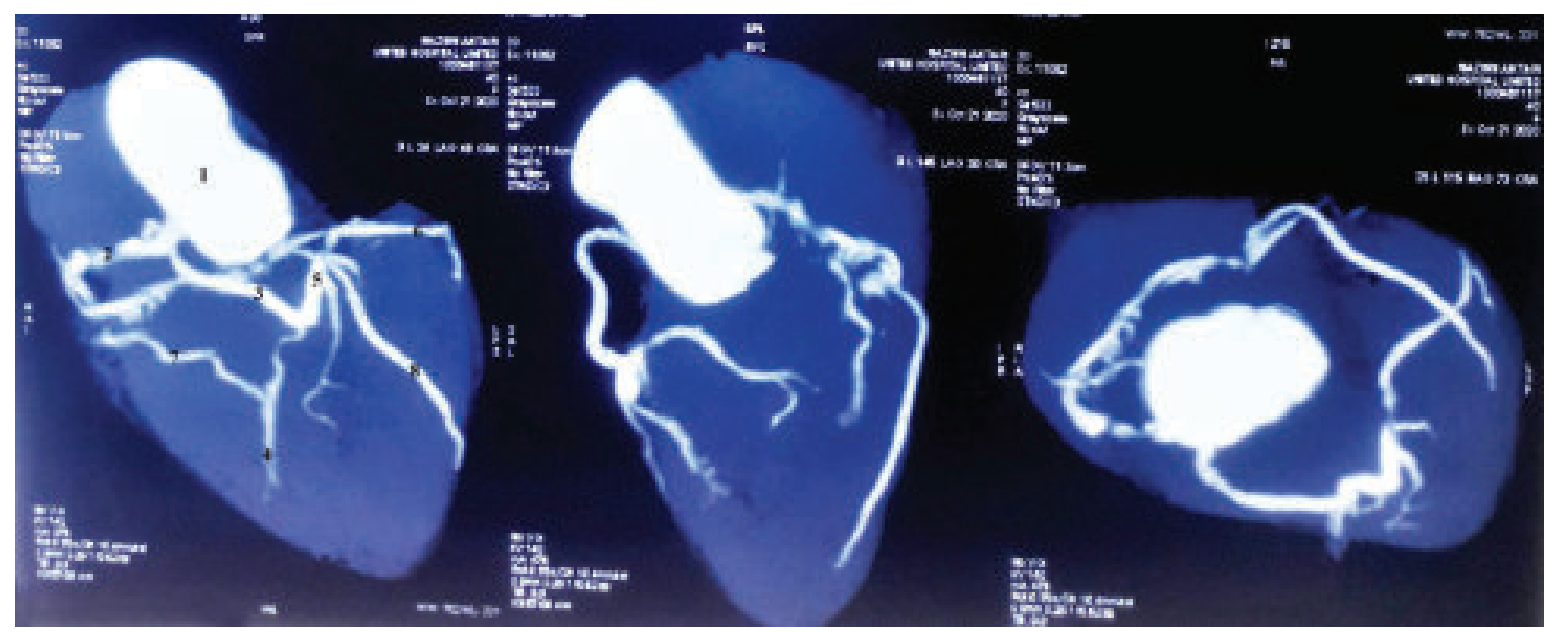

Fig.-3: Computed tomography image of the heart (left) showing the right coronary artery giving rise to the left main coronary artery and the latter's course anterior to the main pulmonary trunk. 1, ascending aorta; 2, right coronary artery; 3, left main coronary artery; 4, left anterior descending artery; 5, left circumflex artery; 6, obtuse marginal branches; 7, early posterior descending artery; 8, postero-lateral vessel. 
Table-I

Lipton's classification for single coronary artery

\begin{tabular}{|c|c|}
\hline Ostia location & Anatomic distribution subtypes \\
\hline $\begin{array}{l}\text { Right sinus of } \\
\text { Valsalva }(R)\end{array}$ & $\begin{array}{l}\mathrm{RI}-\mathrm{SCA} \text { follows the course of a normal RCA } \\
\mathrm{RII}-\mathrm{SCA} \text { from the right sinus gives off an anomalous } \\
\text { transverse branch that crosses the base to } \\
\text { reach the contralateral side } \\
\mathrm{RIII-SCA} \text { from the right sinus, with LAD and LCx } \\
\text { separate coronary trunks instead of } \\
\text { single trunk }\end{array}$ \\
\hline \multirow{2}{*}{\multicolumn{2}{|c|}{$\begin{array}{l}\text { LI_SCA follows the course of a normal LMCA } \\
\text { LII-SCA from the left sinus gives off an anomalous } \\
\text { transverse branch that crosses the base to reach } \\
\text { al side } \\
\text { ling artery; LCx, left circumflex artery; LMCA, left main }\end{array}$}} \\
\hline & \\
\hline Subtyp & $\begin{array}{c}\text { Table-II } \\
\text { of type II single coronary artery based on the course of the aberrant vessel }\end{array}$ \\
\hline Anatomic distribution & SCA subtypes based on course of anomalous transverse branch \\
\hline RII or LII Type A & —courses anterior to the pulmonary trunk \\
\hline Type B & —courses between pulmonary artery and aorta \\
\hline Type P & —courses posterior to the aorta \\
\hline Type S & —septal type courses above the interventricular septum \\
\hline Type C & —combined \\
\hline
\end{tabular}

\section{Discussion:}

Single coronary artery anomaly (SCA) is a congenital anatomic abnormality identified by a single coronary ostium giving rise to all arteries supplying the heart. Single CAA is uncommon and seen in only $0.024-0.06 \%$ of cases. 5 In 1979, Lipton et al.6 provided the angiographic classification of SCA based on the site of ostial location, the anatomical course of the single vessel and relationship of the aberrant transverse branch with respect to the great arteries of the heart. This was further modified by Yamanaka et al.3 in 1990. Single CAA can either be right $(R)$ or left $(L)$ sided corresponding to the ostial location in the right or left sinus of Valsalva. Single CAA are classified into three groups from I to III with Group II consisting of various subtypes based on the course of the aberrant vessel (Tables 1 and 2). Villa et al.7 in 2016 classified CAA functionally as (i) anomalies with obligatory ischaemia, (ii) anomalies without ischaemia, and (iii) anomalies with episodic ischaemia that occasionally cause severe events but are otherwise compatible with normal life. In our case, the patient had congenital SCA; however, her acute presentation was unrelated to the aberrant vessel pathology. Based on the Lipton anatomic classification, the patient illustrated SCA type RIIA with the prepulmonic course of the aberrant vessel (LMCA). Potentially LMCA, RCA, and LAD can all branch from the SCA and take an aberrant course. Type II SCA involving the LMCA is fairly common and is seen in $5 \%$ of patients with tetralogy of

Fallot which can often complicate valve repair. As the vessel crosses the right ventricular outflow tract anteriorly, there are no significant haemodynamic consequences, however, isolated cases of angina have been reported.8 The aberrant vessel can also take an interarterial, 
retroaortic, or septal (sub-pulmonic) route before reaching the left side of the heart. The five potential paths of the aberrant vessel before reaching the perfusion territory, correlate directly with the risk of SCA. Inter-arterial branch coursing between the pulmonary trunk and aorta has an aberrant intramural course within the aortic wall resulting in hypoplasia and lateral compression.9 Inter-arterial course can lead to sudden cardiac death (SCD). The mortality rates of left interarterial arteries (LAD or LMCA) are higher (57\%) compared to right interarterial arteries such as RCA (25\%). In the retroaortic subtype, the aberrant branch courses between the posterior aorta and the interatrial septum which can often complicate aortic valve surgery. This anomaly

usually arises from RCA and is not haemodynamically significant. In the subpulmonic type of SCA, the aberrant branch travels anteriorly and inferiorly through the interventricular septum before coursing through septal myocardium. The subpulmonic type has a lower position, is surrounded by septal myocardium and does not have slit like orifice differentiating it from interarterial course. When diagnosing suspected CAA, it is imperative that an exact anatomical course is established to assess the risk of SCD. The role of TTE in diagnosing CAA is limited. Inclusion of two new screening views by Thankavel et al.10 improved the diagnostic ability of TTE in anomalous coronary artery from opposite sinus from $0.02 \%$ to $0.22 \%$. Currently, coronary CTA and magnetic resonance angiography are Class I indications for diagnosing congenital CAA11 Cardiac

CTA allows for improved, non-invasive visualization of CAA albeit at the expense of radiation and contrast exposure. Superiority of coronary CTA was depicted by Shi et al.12 in a report that showed conventional angiography was diagnostic in only $53 \%$ of CTA proven CAA cases. Magnetic resonance angiography is an alternative that can simultaneously assess structural abnormalities without requiring contrast or harmful radiation exposure however the use remains limited. Coronary angiography remains a useful test to diagnose and classify CAA and is the gold standard for identifying associated coronary artery disease. Traditional angiography offers limited visualization of the coronary ostia, proximal course, and surrounding structures. Ali et al.13 recommended looking for the presence of two signs that should raise suspicion for coronary anomaly (i) the unperfused myocardium sign where the vessel supplying that myocardial territory is not visualized. (ii) The 'aortic root' sign where the vessel appears to cross the aorta and the pulmonary artery at the level of aortic root. In cases with difficult LMCA cannulation, a cuspogram can be performed to visualize the partly opacified artery. When the cuspogram is unsuccessful, right, and non-coronary sinus should be engaged to look for the anomalous origin of LMCA. The 'dot and eye method' was tested by Ishikawa et al.14 to determine the true course of CAA radiologically. The role of non-invasive functional testing to assess the haemodynamic effect of SCA on myocardial perfusion remains controversial.

Both exercise treadmill and stress myocardial perfusion scan can yield false-positives and false-negative results. The use of fractional flow reserve (FFR) and intravascular ultrasound (IVUS) to guide therapy is increasingly gaining attention. Fractional flow reserve can help assess the haemodynamic flow of the aberrant vessel and IVUS can provide an insight on the ostial anatomy. Intravascular ultrasound can help identify slit like or stenosed orifice, acute angle takeoff, and intramural aortic segment (coursing through aortic wall) all of which can increase risk of SCD. Together FFR and IVUS can helps establish the need for intervention especially when the presenting symptoms are atypical. 15

Treatment options include observation with conservative medical management, percutaneous intervention, or surgical repair. Proximal stenosis in cases with SCA can be devastating if adequate collaterals do not exist. The 2008 guidelines for adults with congenital heart disease recommend revascularization or surgical repair of interarterial course regardless of symptoms due to higher rates of myocardial infarction and surgical revascularization on follow-up11 Aberrant vessels with prepulmonic, retroaortic, or transseptal courses have excellent prognosis. Asymptomatic patients with high risk anatomic features and absence of ischaemia on stress testing need multidisciplinary approach.

\section{Conclusion:}

We report a rare case of an incidentally identified SCA with Lipton type RIIA pattern. Although the majority of the patients are asymptomatic further evaluation with coronary CTA is warranted to rule out potential malignant pathology. The risk of SCD is highest with the interarterial course of the aberrant vessel. Stress testing is often not reliable in assessing the functional status of the patient. The optimal approach involves risk stratification, multidisciplinary management, and surgical intervention in appropriate patients.

\section{Conflict of interest: None}




\section{References:}

1. Angelini P. Coronary artery anomalies-current clinical issues: definitions, classification, incidence, clinical relevance, and treatment guidelines. Tex Heart Inst J 2002;29:271-278.

2. Yildiz A, Okcun B, Peker T, Arslan C, Olcay A, Bulent Vatan M. Prevalence of coronary artery anomalies in 12,457 adult patients who underwent coronary angiography. Clin Cardiol 2010;33:E60-E64.

3. Yamanaka O, Hobbs RE. Coronary artery anomalies in 126,595 patients undergoing coronary arteriography. Cathet Cardiovasc Diagn 1990;21:28-40.

4. Angelini P, Villason S, Chan AV, Diez JG. Coronary Artery Anomalies. Baltimore: Lippincott Williams \& Wilkins; 1999.

5. Desmet W, Vanhaecke J, Vrolix M, VAN DE Werf F, Piessens J, Willems J, DE Geest $\mathrm{H}$. Isolated single coronary artery: a review of 50,000 consecutive coronary angiographies. Eur Heart J 1992;13:1637-1640.

6. Lipton MJ, Barry WH, Obrez I, Silverman JF, Wexler L. Isolated single coronary artery: diagnosis, angiographic classification, and clinical significance. Radiology 1979;130:39-47.

7. Villa AD, Sammut E, Nair A, Rajani R, Bonamini R, Chiribiri A. Coronary artery anomalies overview: The normal and the abnormal. World J Radiol 2016;8:537-555.

8. Sanford GB, Molavi B, Sinha AK, Garza L, Angelini P. Single coronary artery with prepulmonic coursing left main coronary artery manifesting as prinzmetal's angina. Tex Heart Inst J 2007;34:449-452.

9. Angelini P, Uribe C, Monge J, Tobis JM, Elayda MA, Willerson JT. Origin of the right coronary artery from the opposite sinus of Valsalva in adults: characterization by intravascular ultrasonography at baseline and after stent angioplasty. Catheter Cardiovasc Interv 2015;86:199-208.

10. Thankavel PP, Lemler MS, Ramaciotti C. Utility and importance of new echocardiographic screening methods in diagnosis of anomalous coronary origins in the pediatric population: assessment of quality improvement. Pediatr Cardiol 2015;36:120-125.

11. Warnes CA, Williams RG, Bashore TM, Child JS, Connolly HM, Dearani JA, Del Nido P, Fasules JW, Graham TP Jr, Hijazi ZM, Hunt SA, King ME, Landzberg MJ, Miner PD, Radford MJ, Walsh EP, Webb GD. ACC/AHA 2008 guidelines for the management of adults with congenital heart disease: a report of the American College of Cardiology/American Heart Association Task Force on Practice Guidelines (Writing Committee to Develop Guidelines on the Management of Adults With Congenital Heart Disease). Developed in Collaboration With the American Society of Echocardiography, Heart Rhythm Society, International Society for Adult Congenital Heart Disease, Society for Cardiovascular Angiography and Interventions, and Society of Thoracic Surgeons. J Am Coll Cardiol 2008;52:e143-e263.

12. Shi $\mathrm{H}$, Aschoff AJ, Brambs HJ, Hoffmann MH. Multislice CT imaging of anomalous coronary arteries. Eur Radiol 2004;14:2172-2181.

13. Ali M, Hanley A, McFadden EP, Vaughan CJ. Coronary artery anomalies: a practical approach to diagnosis and management. Heart Asia 2011;3: 8-12.

14. Ishikawa T, Brandt PW. Anomalous origin of the left main coronary artery from the right anterior aortic sinus: angiographic definition of anomalous course. Am J Cardiol 1985;55:770-776.

15. Angelini P. Novel imaging of coronary artery anomalies to assess their prevalence, the causes of clinical symptoms, and the risk of sudden cardiac death. Circ Cardiovasc Imaging 2014;7:747-754. 